\title{
Alleviating stress in intensive-care unit neonates
}

\author{
TIFFANY FIELD, PH.D.
}

Miami, Florida

Potentially stressful features of the neonatal intensive care unit (NICU) environment, such as continuous noise at high intensity levels ${ }^{1}$ and bright light, ${ }^{2}$ recently have generated concern among neonatal researchers. Rothchild ${ }^{3}$ has speculated that the intensive care nursery may constitute a source of sensory deprivation, while other authors have suggested that the preterm infant may be over stimulated ${ }^{4}$ or may experience an inappropriate pattern rather than an excessive amount of stimulation. ${ }^{5,6}$

A recent volume ${ }^{5}$ on the NICU environment suggests that there is a paucity of documented data on the effects of the intensive care nursery environment per se and even less data on the stressful effects of specific treatment procedures. As Jerold Lucey noted in his foreword to his book, "The prematurely born infant emerges into a hectic, cold noisy, and bright environment filled with mysterious equipment and peopled by masked strangers who try to help. Almost everything done to or for the infant is painful, and that pain can certainly be felt, although it cannot be communicated. The infant who must have an endotracheal tube cannot cry and is not fed by mouth for weeks. His or her feet are slashed periodically for blood samples. The infant's respirator roars away night and day keeping his or her lungs inflated and sustaining life-but at what price?" The preterm neonate appears, then, to be bombarded with multiple and continuous medical procedures, for which the behavioral and physiologic effects on the neonates are virtually unknown at this time.

In one ${ }^{7}$ of the only studies on the stressful effects of specific NICU procedures, invasive measures (such as heelsticks and intubation) and handling (during diaper changes, for example) were investigated. Increased heart rate and decreased $\mathrm{TcPO}_{2}$ were associated with these procedures. Personnel were instructed to use $\mathrm{TcPO}_{2}$ monitoring to modify the care of low birthweight infants or to limit procedures that were considered to be "undesirable time," that is, procedural time that contributed to reduced $\mathrm{TcPO}_{2}$. When monitoring was used, the amount of undesirable time was reduced from 40 minutes to 6 minutes per 20 hours. Infants in the monitored group were handled less frequently and experienced less hypoxemia (Fig. 1).

More recently, other procedural stressors, including neurobehavioral assessments that involve reflex testing and repositioning of the infant, have been investigated. The Brazelton Neonatal Behavioral Assessment Scale (NBAS) for example, is conducted routinely in many neonatal intensive care nurseries just prior to the preterm infant's discharge. Data from a study by Gunnar and coworkers ${ }^{8}$ suggest that cortisol levels were elevated following the administration of the Brazelton Scale, which indicates that these assessments are stressful to the newborn. Neurobehavioral assessments of preterm neonates who have been treated in the NICU may be even more stressful. Although the NBAS frequently is used for pretermers just prior to discharge, when they approximate term gestational age, several neonatal researchers have noted behavioral distress in these neonates during and following the test. However, the physiologic effects of the stressor have not been documented.

A physiologic index of stress, which has not previously been used with preterm infants, is growth hormone levels. While growth hormone values typically are elevated in stressed adults and children, stress-associated growth hormone levels are diminished in infants. ${ }^{9} \mathrm{~A}$ serendipitous finding in our (Schanberg and Field's ${ }^{10}$ ) 1986 study on the effects of stimulation suggests that preterm neonates are stressed by neurobehavioral assessments, as manifested by decreased growth hormone levels. Eight preterm neonates (mean gestational age $=31$ weeks, mean body weight $=1,280 \mathrm{gm}$., and NICU time $=20$ days) were studied. At the time of the neonatal assessment, the infants averaged 36 weeks' postconceptional age and 1,662 grams' weight. The infants were given heelsticks for plasma samples of growth hormone levels on the day prior to the administration of the NBAS and 2 hours following the assessment. The mean baseline value for plasma growth hormone was $21.5 \mathrm{ng} . / \mathrm{ml}$, and the mean growth hormone value post-NBAS was $14.4 \mathrm{ng} . / \mathrm{ml}$. Table 1 lists

TABLE 1. PLASMA LEVEL OF GROWTH HORMONE (NG./ML.) AT BASELINE AND POSTBRAZELTON ASSESSMENT. ${ }^{10}$

\begin{tabular}{|lccc|} 
Neonate & $\begin{array}{c}\text { Baseline } \\
\text { value }\end{array}$ & $\begin{array}{c}\text { Post-Brazelton } \\
\text { value }\end{array}$ & $\begin{array}{c}\text { Percentage } \\
\text { of change }\end{array}$ \\
\hline 1 & $26.0(27,25)$ & 19.0 & -27 \\
2 & $20.0(20,20)$ & 12.0 & -40 \\
3 & $29.5(31,28)$ & 14.0 & -53 \\
4 & $19.5(18,21)$ & 9.0 & -54 \\
5 & $19.0(17,21)$ & 9.0 & -24 \\
6 & $25.0(31,19)$ & 19.0 & -4 \\
7 & $13.5(12,15)$ & 13.0 & -4 \\
8 & $19.5(25,14)$ & 19.0 & -32 \\
& & & (S.E. $\pm 7, p<.02)$ \\
\hline
\end{tabular}

the neonates' individual values. The difference value $(\mathrm{M}=-7.1$, S.E. \pm 1.8$)$ was significant at $p<.02$. The 32 percent decrease in growth hormone following administration of the NBAS suggests that assessments of this kind are stressful to preterm newborns even when they are given just prior to discharge at approximately term age. pear to be manifested by distress behavior and altered physiologic and adrenal corticol activity. These findings have contributed to the "minimal touch" policy adopted by many intensive care nurseries, which try to limit the number of stressful procedures as well as the periodicity of them. In addition, investigators ${ }^{11,12}$ are actively attempting to design less stressful neurobehavioral as-

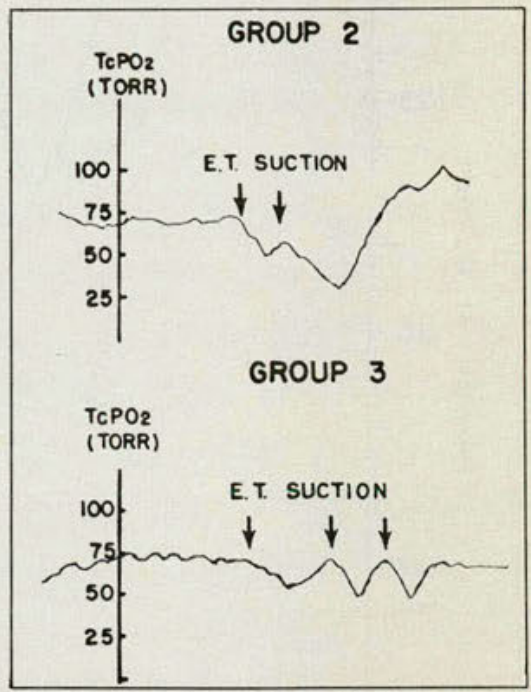

Fig. 1. Sample tracing of changes in $\mathrm{TcPO}_{2}$ versus time following endotracheal suctioning. (From Long and associates, ${ }^{7}$ with permission.)
Thus, these stressful experiences ap- 


\begin{tabular}{|l|cc|}
\hline \multicolumn{4}{|l|}{ TABLE 2. PLASMA LEVELS OF CORTISOL (NG./ML.) AT DAY 1 AND DAY 5 FOLLOWING } \\
WEANING FROM VENTILATOR. ${ }^{\circ}$
\end{tabular}

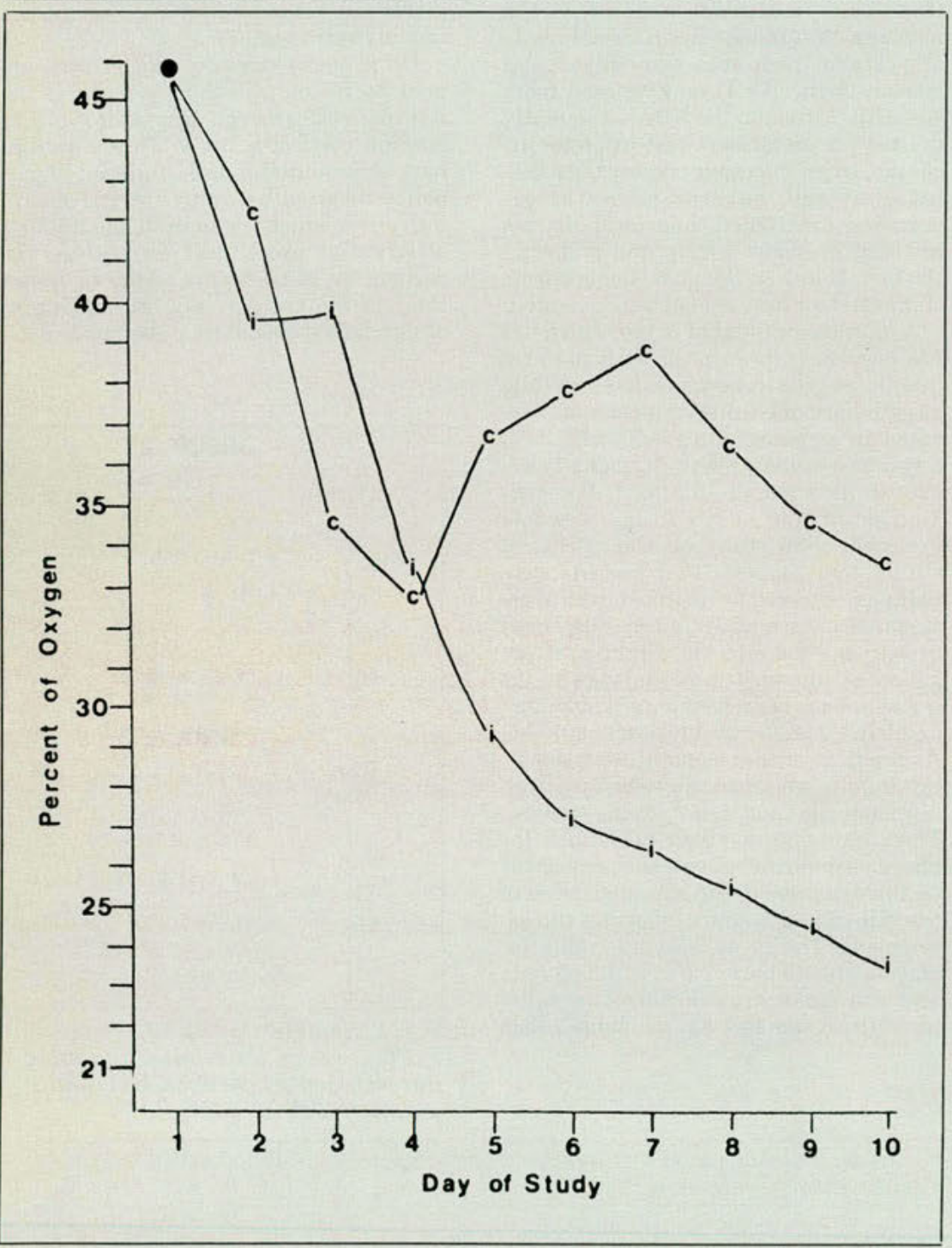

Fig. 2. Mean inspired oxygen $\left(\mathrm{F}_{1} \mathrm{O}_{2}\right)$ over time of intervention and control groups. (From Jay, ${ }^{14}$ with permission.)

sessments for the preterm neonate that involve less handling of the neonate as well as shorter assessment protocols.

Many NICU treatment procedures (intubation, ventilation, and heelsticks) are, of course, necessary for the survival and ample, we (Field and Goldson ${ }^{13}$ ) reported significant elevations in heart rate and respiration associated with the heelstick procedure. Similarly, weaning from mechanical ventilation appears to be stressful, as manifested by elevated cortisol levels on the day following the procedures.

The stressful effects of weaning was another finding in our 1986 study. ${ }^{10}$ The protocol included plasma sampling via heelsticks on days $1,5,9$, and 10 of the stimulation study. The neonates were weaned from the ventilators 1 to 2 days prior to their participation in the study. As can be seen in Table 2, plasma levels of cortisol were significantly higher on day 1 $(\mathrm{M}=61 \mathrm{ng} . / \mathrm{ml}$.) than on day $5(\mathrm{M}=41$ $\mathrm{ng} . / \mathrm{ml}$.). Because, there was no significant difference among the levels of cortisol on days $5,9,10$, which suggested stability of cortisol levels over that period, the data from these three days were averaged and compared to day 1 . The percentage change from day 1 to the mean of days 5,9 , and 10 was a 25 percent decrease in cortisol values-a decrease that was significant at $p<.05$. Thus, although it would be important to investigate the difference between baseline levels taken prior to weaning from the ventilator and those taken subsequent to the procedure, these findings suggest that the weaning process is stressful.

For those medical procedures that are necessary, the question arises as to whether various forms of soothing stimulation can be applied during them to alleviate their stressful effects. Natural caregiving stimulation, such as stroking the infant, and natural self-comforting behavior by the infant, such as sucking, appear to be examples of effective alleviators of stressful NICU experiences.

A study designed to provide natural caregiving stimulation was conducted by Jay. ${ }^{14}$ For this study, a nursing intervention of planned, intermittent, gentle tactile contact was designed specifically for very-short-gestation infants who required mechanical ventilation. Each of the 13 infants in the intervention group received 48 minutes of tactile contact per day. A clinical nurse specialist simply placed her hands on the infant's head and abdomen for 12 minutes 4 times daily. The 12-minute periods were planned around the infants' nursing and medical care to avoid interruption of the touching periods. An objective of the intervention, according to the author, was to provide the infant with periods of gentle human touch during which the child would not experience coexisting painful stimuli. This simple placing of hands on the preterm neonate's head and abdomen was associated with a decreased need for mechanical ventilation (Fig. 2), fewer startle responses (Fig. 3), and fewer clenched fists (Fig. 4) for stimulated infants.

In a more extensive touching intervention by Field and associates, ${ }^{15}$ we arranged for preterm neonates to be provided with 45 minutes per day (for 10 days) of stroking and passive movements 


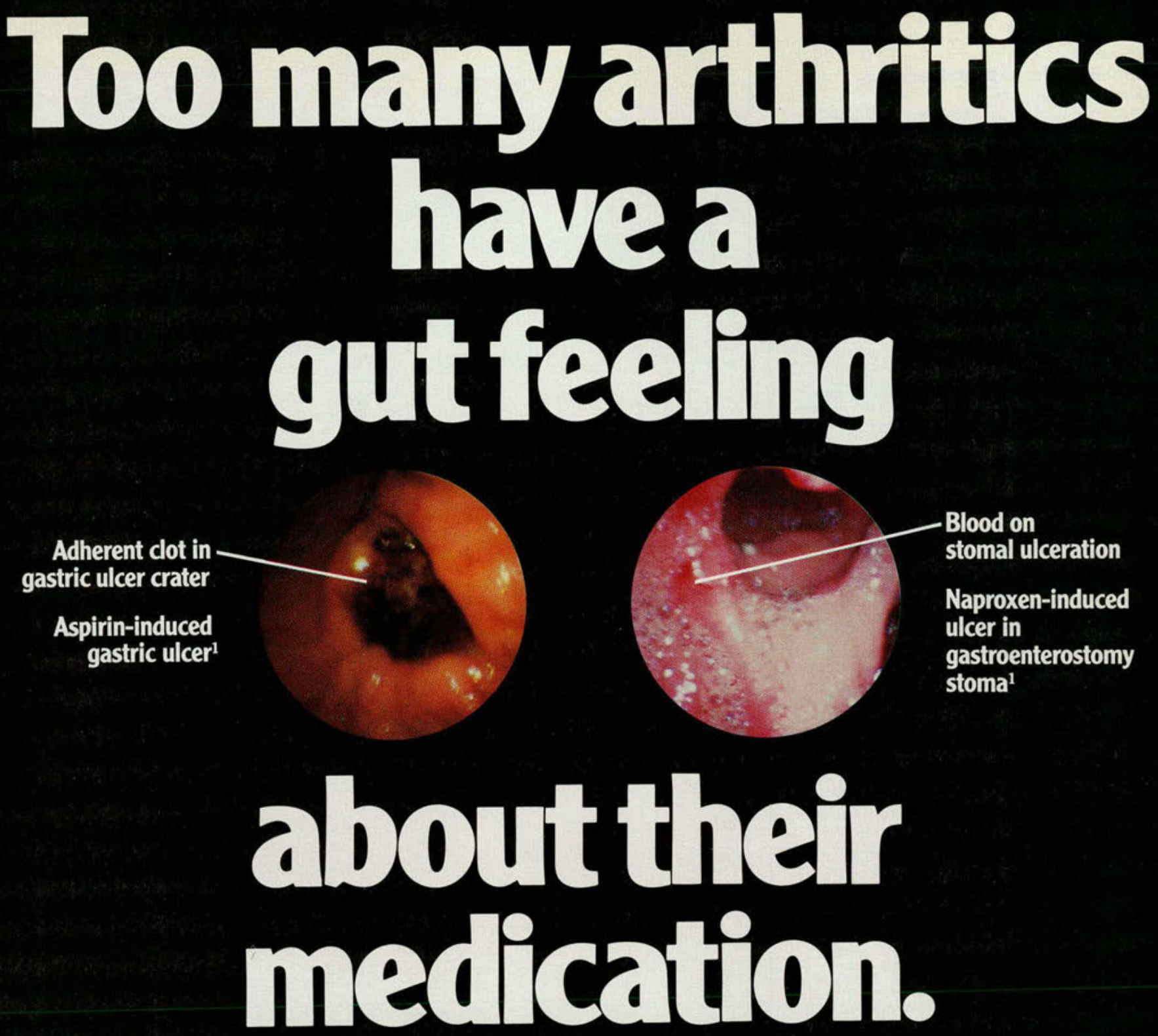

\section{Disalcid ${ }^{\circledR}$ avoids severe $\mathrm{GI}$ side} effects without loss of efficacy. Doses of aspirin high enough to provide anti-inflammatory activity can also produce $\mathrm{Gl}$ irritation, erosion and bleeding. A similar side effect profile is seen with naproxen, ibuprofen, indomethacin and other NSAIDs. These side effects are thought to be related to a nonselective inhibition of prostaglandin synthesis.

\section{Disalcid selectively spares prostaglandins for a better safety profile.}

A recent study showed that Disalcid suppresses serum prostaglandin $E_{2}$ (which provides cytoprotection of the gastric mucosa) by only $18 \%$, while aspirin completely suppresses it. ${ }^{2}$ For this reason, Disalcid has less potential for serious gastric side effects.

\section{$79 \%$ show improvement when switched to Disalcid.}

In a 15-day study, ${ }^{3} 182$ arthritics were switched from a variety of medications to two $750 \mathrm{mg}$ Disalcid tablets b.i.d. Of these patients, $79 \%$ showed a reduction in disease symptoms, with a $65 \%$ decrease in drug-related side effects.

Disalcid. Anti-inflammatory activity comparable to that of aspirin ${ }^{4.5}$ yet so safe that NSAID-induced gastric ulcers actually heal during therapy. ${ }^{1}$

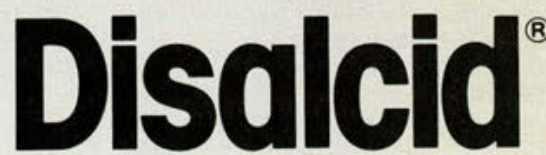

(salsalate) Tablets and

\section{The antiarthritic to prescribe first.}

Please see next page for prescribing information. ๑ Riker Laboratories, Inc.-1986 


\section{Disalcid}

(salsalate) Tablets an

The antiarthritic to prescribe first.

\section{CONTRAINDICATIONS}

DISALCID is contraindicated in patients hypersensitive to salsalate.

\section{WARNINGS}

Reye Syndrome may develop in individuals who have chicken pox, influenza, or flu symptoms. Some studies suggest a possible association between the development of Reye Syndrome and the use of medicines containing salicylate or aspirin. Disalcid contains a chicken pox, influenza, or flu symptoms.

\section{PRECAUTIONS}

General Precautions. Patients on long-term treatment with DISALCID should be warned not to take other salicylates so as to avoid potentially toxic concentrations. Great care should be exercised when DISALCID is prescribed in the presence of chronic rena insufficiency. Protein binding of salicylic acid can be influenced by nutritional status, competitive binding of other drugs, and fluctuations in serum proteins caused by disease (rheumatoid arthritis, etc.). Laboratory Tests. Plasma salicylic acid concentrations should be periodically monitored during long-term treatment with DISALCID to aid maintenance of therapeutically effective levels: 10 to 30 $\mathrm{mg} / 100 \mathrm{ml}$. Toxic manifestations are not usually seen until plasma concentrations exceed $30 \mathrm{mg} / 100 \mathrm{ml}$ (see OVERDOSAGE). Urinary $\mathrm{pH}$ should also be regularly monitored: sudden acidifica tion, as from pH 6.5 to 5.5, can double the plasma level, resulting in toxicity. Drug Interactions. Salicylates antagonize the uricosuric action of drugs used to treat gout. Aspirin and other salicylate drugs will be additive to DISALCID and may increase plasma concentrations of salicylic acid to toxic levels. Drugs and foods that raise urine $\mathrm{pH}$ will increase renal clearance and urinary excretion of salicylic acid, thus lowering plasma levels; acidifying drugs or foods will decrease urinary excretion and increase plasma levels. Salicylates may competitively displace anticoagulant drugs from plasma protein bindin sites and thereby predispose to systemic bleeding. Salicylates may enhance the hypoglvcemic effect of oral antidiabetic drugs of the sulfonylurea class. Salicylate competes with a number of drugs for protein binding sites, notably penicillin, thiopental, thyroxine, triiodothyronine, phenytoin, sulfinpyrazone, naproxen, warfarin methotrexate, and possibly corticosteroids. Drug/Laboratory Test Interactions. Salicylate competes with thyroid hormone for binding to plasma proteins, which may be reflected in a depressed plasma $\mathrm{T}_{4}$ value in some patients; thyroid function and basal metabolism are unaffected. Carcinogenesis. No long-term animal studies have been performed with DISALCID to evaluate its carcinogenic potential: however, several such studies using aspirin and other salicylates have failed to demonstrate any association of these agents with cancerous cell changes. Use in Pregnancy. Pregnancy Category C: Salsalate and salicylic acid have been shown to be teratogenic and embryocidai in rats when given in doses 4 to 5 times the usual human dose. These great as the usual human dose. There are no adequate and well. controlled studies in pregnant women. DISALCID should be used during pregnancy risk to the fetus. Labor and Delivery. There exist no adequate and well-controlled studies in pregnant women. Although adverse effects on mother or infant have not been reported with DISALCID use during labor, caution is advised when anti-inflammatory dosage is involved. However, other salicylates have been associated with prolonged gestation and labor, maternal and neonatal bleeding sequelae, potentiation of narcotic and barbiturate effects (respiratory or cardiac arrest in the mother), delivery problems and stillbirth. Nursing Mothers. It is not known whether salsalate per se is excreted in human milk; salicylic acid, the primary metabolite of DISALCID, has been shown to appear in human milk in concentrations approximating the maternal blood level. Thus the intant of a mother on DISALCID therapy might ingest in mother's milk 30 to $80 \%$ as much salicylate per $\mathrm{Kg}$ body weight as the mother is taking. Accordingly, caution should be exercised when DISALCID is administered to a nursing woman. Pediatric Use. Safety and effectiveness in children have not been established.

\section{ADVERSE REACTIONS}

Auditory system. Tinnitus and temporary hearing loss can occur. Tinnitus probably represents blood salicylic acid levels reaching or exceeding the upper limit of the therapeutic range. It is therefore a helpful guide to dose titration. Temporary hearing loss disappears gradually upon discontinuation of the drug. Gastrointestinal system.

\section{DRUG ABUSE AND DEPENDENCE}

Drug abuse and dependence have not been reported with DISALCID. OVERDOSAGE

No deaths after overdosage have been reported for DISALCID. Death has followed ingestion of 10 to $30 \mathrm{~g}$ of other salicylates in adults, but much larger amounts have been ingested without fatal outcome. The oral $\mathrm{LD}_{50}$ for DISALCID in rats is approximately $2000 \mathrm{mg} / \mathrm{kg}$ (sixty times the recommended maximum single dose for adults). Symptoms: The usual symptoms of salicylism-tinnitus, vertigo headache, confusion, drowsiness, sweating, hyperventilation vomiting and diarrhea - will occur. More severe intoxication will lead to disruption of electrolyte balance and blood pH, and hyperthermia

Ireatment: Further absorption of DISALCID from the G.I. tract should be prevented by emesis (syrup of ipecac) and, if necessary, by gastric lavage.

Fluid and electrolyte imbalance should be corrected by the administration of appropriate I.V. therapy. Adequate renal function should be maintained. Hemodialysis or peritoneal dialysis may be required in extreme cases.

References: 1. Voltin RF: NSAIDs from a G.I. point of view. Praclica Gastroenterology July/Aug 1984:8:33-34 2. Disalcid Study 024. Data on file, Medical Department, Riker Laboratories, Inc. 3. NcPherson TC: Salsalate for arthritis: A clinical evaluation. Clin Ther 1984,6:388-403 4. Aberg G, Larsson KS: Pharmacological properties of some antirheumatic salicylates. Acla Pharmacol Toxicol 1970-28:249.5. Liyanage SP. Tambar PK: Comparative study of salsalate and aspirin in osteoarthritis of hip or knee. Curr Med Res Opin 1978:5(6):450.

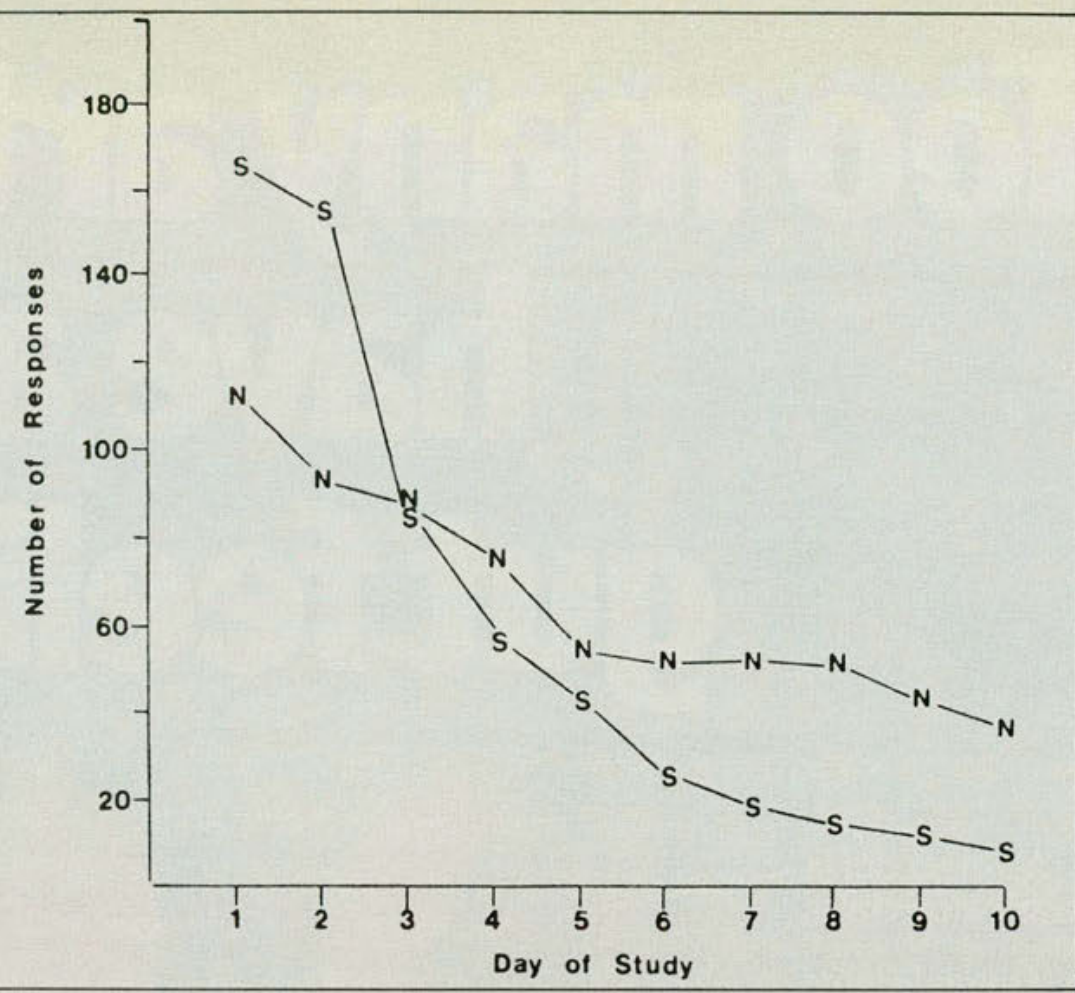

Fig. 3. Frequency of startle responses and nonstartle responses over time in the intervention group during touch periods. (From Jay, ${ }^{14}$ with permission.)

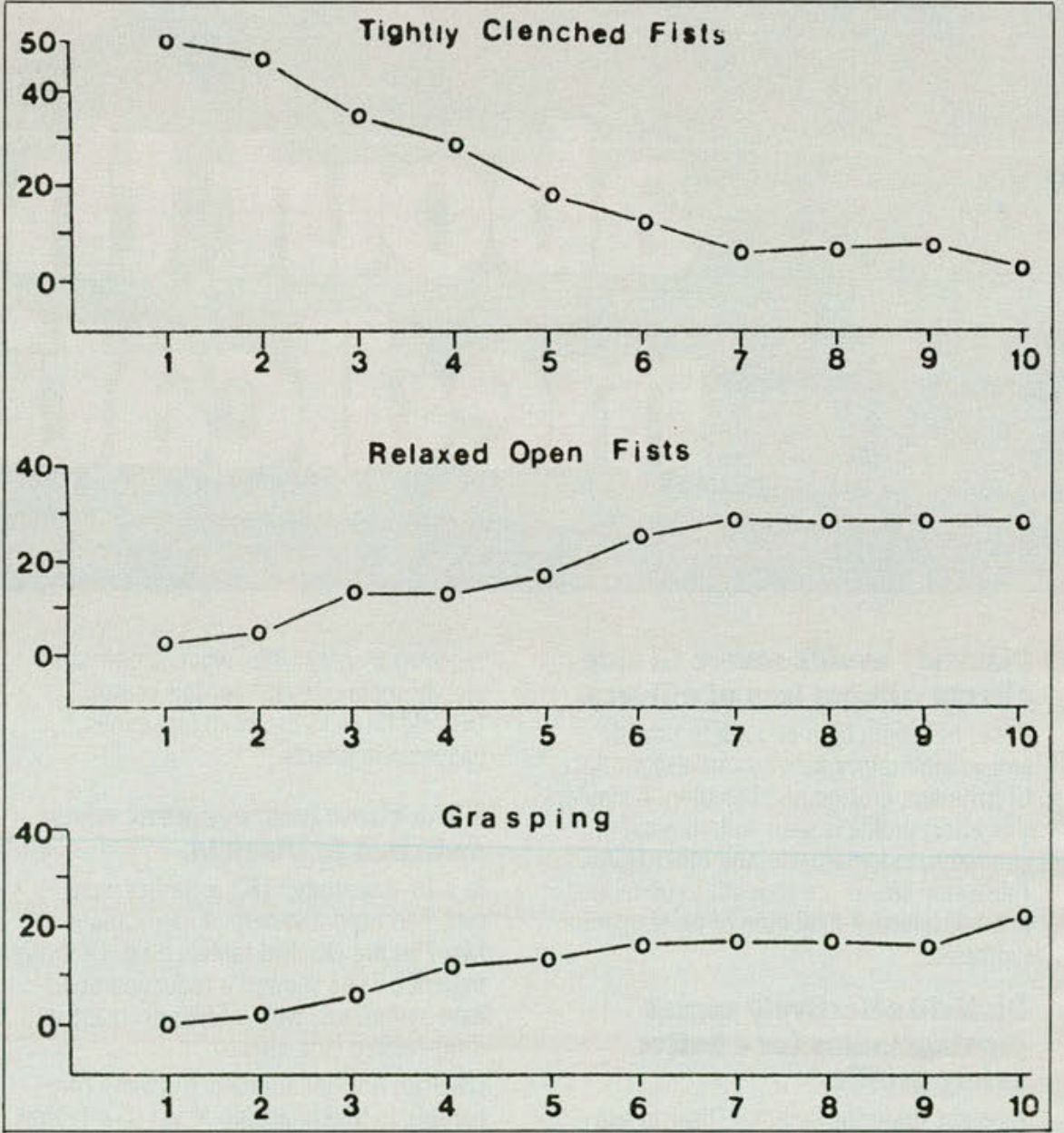

Fig. 4. Predominance of fine hand activity over time in the intervention group during touch periods. (From Joy, ${ }^{14}$ with permission.) 
of the limbs. For this study, 40 preterm neonates were assigned randomly to a treatment or control group. The groups were comparable as to gestational age (M $=31$ weeks $)$, birthweight $(\mathrm{M}=1,280$ $\mathrm{gm}$.$) , and duration of intensive care ( \mathrm{M}=$ 20 days). The neonates were chosen at the time they entered the transitional "grower" nursery. The treatment group received tactile/kinesthetic stimulation for three 15-minute periods during 3 consecutive hours per day for 10 days. The stimulation sessions were composed of three 5-minute phases. During the first and third phases, tactile stimulation was provided. The prone neonate received body stroking of the head and face region, neck and shoulders, back, legs, and arms for five 1-minute segments. The kinesthetic stimulation phase involved gentle flexing of the supine infant's limbs. Clinical data, including formula intake and weight gain, were recorded daily. Each neonate was given the NBAS and his/her sleep/wake behavior was recorded at the end of the 10-day treatment period. The behavior observations were conducted over a 45 -minute period, during which sleep states were coded as well as behaviors such as limb movements and facial expressions.

The data analysis (Table 3 ) suggested the following: (1) the stimulated infants averaged 47 percent greater weight gain per day, even though the groups did not differ in average formula intake (the volume of calories); (2) the treatment infants were awake and active a greater percentage of the behavioral observation time; (3) the stimulated infants showed more mature habituation, orientation, motor activity, and range of state behavior on the Brazelton scale; and (4) the stimulated infants were hospitalized 6 days less than the control infants, which yielded an average hospital cost saving of $\$ 3,000$ per infant. Thus, the data from the studies by Jay $^{14}$ and Field and associates ${ }^{15}$ combine to suggest that simple forms of tactile stimulation may alleviate the stress and facilitate the clinical course of preterm infants who have been treated in the NICU.

The infant, on its own accord, apparently can also effectively modulate stressful experiences by self-comforting behaviors such as sucking. Because of the effectiveness of non-nutritive sucking in calming neonates, we conducted a study (Field and Goldson ${ }^{13}$ ) in which NICU and minimal care preterm neonates were given pacifiers during heelsticks. The infants who were allowed to suck on the

TABLE 3. MEANS FOR MEASURES DIFFERENTIATING TACTILE KINESTHETIC STIMULATION PRETERM NEONATES FROM CONTROLS. ${ }^{15}$

\begin{tabular}{|lccl|}
\hline & \multicolumn{2}{c}{ Groups } \\
\cline { 2 - 3 } Measures & Stimulation & Control & $p$ level \\
\hline Feedings (no. per day) & 8.6 & 9.0 & NS \\
Formula (cc./kg./day) & 171.0 & 166.0 & NS \\
Calories/kg./day & 114.0 & 112.0 & NS \\
Calories/day & 169.0 & 165.0 & NS \\
Daily weight/gain (gm.) & 25.0 & 17.0 & .0005 \\
Time awake (percent) & 16.0 & 7.0 & .04 \\
Time movement (percent) & 32.0 & 25.0 & .04 \\
Brazelton scores & & & \\
Habituation & 6.1 & 4.9 & .02 \\
Orientation & 4.8 & 4.0 & .02 \\
Motor activity & 4.7 & 4.2 & .03 \\
Range of state & 4.6 & 3.9 & .03 \\
\hline
\end{tabular}

pacifier showed less fussing and crying both during and after the procedure than those not given pacifiers (Table 4). In addition, the minimal care neonates who were provided pacifiers were less physiologically aroused by the heelstick procedure, as manifested by lower heart rate and respiration rate. Although the NICU neonates who were given pacifiers also cried less, their heart rate and respiration were unaffected by the sucking treatment. This inconsistency in the treatment effects of behavioral and physiologic arousal was interpreted as a lack of cardiac-somatic coupling in the ICU neonates. Thus, non-nutritive sucking during heelsticks appeared to attenuate behavioral distress in all neonates and physiologic arousal in more mature neonates with less severe neonatal complications.

Gavage or tube feeding is another stressful procedure during which nonnutritive sucking appears to effectively calm the neonate. In another of our studies (Field and coworkers ${ }^{16}$ ), a sample of 57 infants admitted to the NICU were assigned randomly to treatment and control groups. The groups were equivalent on gestational age ( $M=32$ weeks), birthweight $(\mathrm{M}=1,300 \mathrm{gm}$.$) , and postnatal$ complications. Neonates in the treatment group were given a pacifier during all tube feedings. The treatment group required fewer tube feedings than did the control group. Their average weight gain per day was also greater, they were hospitalized fewer days, and their hospital costs were significantly lower (Table 5). In addition, infants in the treatment group were easier to feed during later bottle feedings, as manifested by the nurses having to engage in fewer stimulating behaviors, such as bottle jiggling and changes of feeding position.

Thus, natural caregiving stimulation, such as gentle stroking, and self-comforting stimulation, such as sucking, appeared to attenuate distress behavior and physiology during stressful NICU procedures. Inasmuch as these interventions are easy to provide during invasive procedures, and given that they not only temporarily soothe the stressed infant, but also have positive side effects such as increased weight gain and shorter hospital stay, they would appear to be cost-effective stress alleviators for the NICU neonate.

1. Gottfried, A.W., et al:: Physical and social environment of newborn infants in special care units. Science 214:673-5, Nov 81

2. Glass, P., et al.: Effect of bright light in the hospital nursery on the incidence of retinopathy of prematurity. N Engl J Med 313:401-4, 15 Aug 85

3. Rothchild, B.T.: Incubator isolation as a possible contributing factor to the high incidence of emotional disturbance among premature born persons. J Genetic Psychol 110:287-304, 1966 4. Cornell, E.H., and Gottfried, A.W.: Intervention with premature human infants. Child Dev

TABLE 4. MEANS FOR MEASURES TAKEN DURING HEELSTICKS FOR TREATMENT (NON-NUTRITIVE SUCKING) AND CONTROL GROUPS IN MINIMAL INTENSIVE CARE NURSERIES. ${ }^{13}$

\begin{tabular}{|c|c|c|c|c|c|c|}
\hline \multirow[b]{2}{*}{ Measures } & \multicolumn{2}{|c|}{ Minimal care } & \multicolumn{3}{|c|}{ Intensive care } & \multirow[b]{2}{*}{$p$} \\
\hline & Treatment & Control & $p$ & Treatment & Control & \\
\hline Crying time (percent) & 25 & 41 & .005 & 01 & 19 & .001 \\
\hline Heart rate (beats per minute) & 172 & 187 & .05 & 165 & 168 & NS \\
\hline Respiration rate (per minute) & 81 & 72 & .05 & 51 & 54 & NS \\
\hline
\end{tabular}


For two years, we've told

millions of hay fever sufferers

to see their doctors.

Now, thanks to you, they're putting their hay fever to sleep while they stay awake.

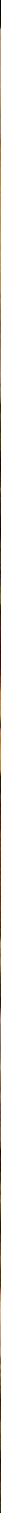

National television, print, and radio advertising told millions of hay fever sufferers to see their doctors for symptom relief without the degree of drowsiness often associated with anti-allergy products.

Merrell Dow Pharmaceuticals Inc. 
TABLE 5. MEANS FOR CLINICAL OUTCOME MEASURES AND BRAZELTON SCORES OF TREATMENT GROUP RECEIVING NON-NUTRITIVE SUCKING STIMULATION AND CONTROL GROUP, ${ }^{16}$

\begin{tabular}{|lrrr|} 
Measures & Treatment & Control & $p$ \\
\hline Number of tube feedings & 219.0 & 246.0 & .05 \\
Days of tube feeding & 26.0 & 29.0 & .01 \\
Daily weight gain (gm.) & 19.3 & 16.5 & .05 \\
Number of hospital days & 48.0 & 56.0 & .05 \\
Hospital cost & $16,800.0$ & $20,294.0$ & .01 \\
\hline
\end{tabular}

\section{7:32-9, Mar 76}

5. Gottfried, A.W., and Gaiter, J.L.: Infant stress under intensive care. University Park Press, Baltimore, 1985

6. Lawson, K., Daum, C., and Turkewitz, G.: Environmental characteristics of neonatal intensive-care unit. Child Dev 48:1633-9, Dec 77 7. Long, J.G., et al.: Excessive handling as a cause of hypoxemia. Pediatrics 65:203-7, Feb 80 8. Gunnar, M.R., Isensee, J., and Fust, S.: Adrenocorticol activity and the Brazelton neonatal Assessment Scale. Moderating effects of the newborn's biobehavioral status. Child Dev. (In press)

9. Stubbe, P. and Wolf, M.: The effect of stress on growth hormone, glucose and glyceral levels in newborn infants. Hormone Metab Res 3:175-9, 1971

10. Schanberg, S., and Field, T:: Sensory deprivation stress and supplemental stimulation in the rat pup and the preterm human neonate. Child Dev, in press

11. Als, H., et al.: Toward a research instrument for the assessment of preterm infants' behavior (APIB). In Theory and research in behavioral pediatrics, edited by N.E. Fitzgerald, B.M. Lester, and M.W. Togman. Plenum Publishing
Corp., New York, 1982, vol. 1

12. Korner, A.: Neurobehavioral maturity assessment for preterm infants. Unpublished manual, 1986

13. Field, T., and Goldson, E.: Pacifying effects of nonnutritive sucking on term and preterm neonates during heelstick procedure. Pediatrics $74: 1012-5$, Dec 84

14. Jay, S.: The effects of gentle human touch on mechanically ventilated very short gestation infants. Maternal-Child Nurs J 11:199-256, 1982

15. Field, T., et al.: Tactile/kinesthetic stimulation effects on preterm neonates. Pediatrics 77:654-8, May 86

16. Field, T., et al.: Nonnutritive sucking during tube feedings. Effects on preterm neonates in an ICU. Pediatrics 70:381-4, Sep 82

Dr. Field is professor of pediatrics and psychology, Departments of Pediatrics and Psychology, Mailman Center for Child Development, University of Miami Medical School, P.O. Box 016820, Coral Gables, Florida 33124 